NOTE: THIS IS A POSTPRINT. PLEASE CITE PUBLISHED VERSION.

https://doi.org/10.1007/s11158-019-09420-9

ABSTRACT: Many moral and political theorists have recently argued that the fact that an agent has innocently benefited from wrongdoing or injustice can ground special moral duties to help out the victims or simply give up the benefits. This idea is often referred to as the "Beneficiary Pays Principle" (BPP). This article critically assesses three recent attempts at providing a rationale for the BPP and argue that there are profound problems with each of them. It argues that even if we accept plausible versions of the different normative ideas these accounts appeal to, we have no reason to accept the BPP. 


\section{What is the wrong in retaining benefits from wrongdoing? How recent attempts to formulate a plausible rationale for the "Beneficiary Pays Principle" have failed}

\section{Introduction}

Suppose I run you over with my car. It is not an accident, and it is not a case of me having some reasonable reason for hitting you, such as attempting to avoid ramming into several children on their way to school. Instead it is a case of me not caring about what happens to you. I simply prefer the exhilarating feeling of acceleration over the dullness of stopping just for the sake of avoiding harming you. As a result, you have to spend the best part of the next three years in hospitals, recovering from your injuries.

It seems that due to these circumstances, I owe you something as compensation or repair for what I did to you. According to this view, an agent who is responsible for inflicting wrongful harm has special moral reasons to compensate the victims of their wrongdoing. As moral principles go, this one seems more or less uncontroversial. Now suppose instead that I hit you with my car because my friend Peter would stand to benefit from you being hit by a car. For instance, suppose that you were on your way to an interview for a job that entailed the kind of lucrative opportunity for you that you are unlikely to have again. You were the standout candidate for the position and Peter (who knew nothing of my intentions to run you over) was the second-best candidate. Suppose that six months later, I call Peter and tell him how I ran you over in order to help secure the job for him. Furthermore, I tell him that since there were no witnesses, I got away with it. Seconds later I die in a car crash, leaving nothing 
of value.

Peter, of course, is wholly innocent of my wrongdoing. However, he has benefited from it. It seems that Peter surely has weighty moral reason to inform both you and the police about what happened. Could it also be that Peter, similarly to someone who contributes to wrongdoing, also has special moral reasons to provide some form of compensation for you by virtue of his standing as an innocent beneficiary of wrongdoing $?^{1}$

In recent years, quite a few moral theorists have argued that the answer to such a question is yes. ${ }^{2}$ This idea has been referred to as "the principle of wrongful benefits", "the beneficiary principle" or "the beneficiary pays principle" (BPP). ${ }^{3}$ As is often argued, the BPP may have practical implications for questions about compensation for historical injustices like colonialism and slavery, for questions of what members of rich countries owe those that are wronged by harmful international institutions, and for questions about how to distribute

\footnotetext{
${ }^{1}$ Note that this would only hold at least up to the point where he has no longer benefited from the wrong.

${ }^{2}$ See e.g. Christian Barry and R. E. Goodin, "Benefiting from the wrongdoing of others", Journal of Applied Philosophy, 31 (2014), pp. 363-376; Christian Barry and David Wiens, "Benefiting from wrongdoing and sustaining wrongful harm”, Journal of Moral Philosophy, 13 (2016), pp. 530-52; Daniel Butt, "On benefiting from injustice", Canadian Journal of Philosophy, 37 (2007), pp. 129-52; Daniel Butt, Rectifying international injustice: Principles of compensation and restitution between nations (Oxford: Oxford University Press, 2008); Daniel Butt, "“'A doctrine quite new and altogether untenable”: Defending the beneficiary pays principle”, Journal of Applied Philosophy, 31 (2014), pp. 336-48; Robert. E. Goodin, "Disgorging the fruits of historical wrongdoing”, American Political Science Review, 107 (2013), pp. 478-91; Bashar Haydar and Gerhard Øverland, "The normative implications of benefiting from injustice", Journal of Applied Philosophy, 31 (2014), pp. 349-62; Tom Parr, “The moral taintedness of benefiting from injustice”, Ethical Theory and Moral Practice, 19 (2016), pp. 985-97. An earlier defense of the same view is found in Judith Jarvis Thomson, "Preferential hiring”, Philosophy \& Public affairs, 2 (1973), pp. 364-84.

${ }^{3}$ I will refer to this idea as the "beneficiary pays principle" (BPP).
} 
burdens related to mitigating or adapting to climate change. ${ }^{4}$

When applied to hypothetical cases like the one above, the BPP arguably sounds very intuitively plausible. Many seem to believe that innocent beneficiaries of wrongs, such as Peter, are in a different position than other equally innocent agents, meaning that they have some particularly pressing moral reason to help the victim up to the point where they have no longer benefited from the wrongdoing. ${ }^{5}$ In fact, I am inclined to count myself among them. However, a beneficiary of a wrong such as Peter may object to the idea that people's mere intuitions about what he should do are particularly relevant. He may point to the fact that he is innocent of any wrongdoing, which seems to make it unclear why he has more pressing responsibilities than innocent agents in general. This is not a challenge that can be ignored. Justification in normative theory seem to require more than appeals to intuitions about sets of cases. Arguably, for there to be really good reasons to accept the BPP, a plausible normative rationale should back it up as well. However, other than in cases of possession of stolen property, it is not so obvious what the wrong in pocketing our benefits from wrongs could amount to. 6

\footnotetext{
${ }^{4}$ For BPP and climate justice, see e.g. Axel Gosseries, "Historical emissions and free-riding”, Ethical Perspectives, 11 (2004), pp. 36-60; Holly Lawford-Smith, "Benefiting from failures to address climate change", Journal of Applied Philosophy 31 (2014), pp. 392-404; Edward Page, "Give it up for climate change: A defence of the beneficiary pays principle", International Theory, 4 (2012), pp. 300-30; Henry Shue, "Global Environment and International Inequality”, International Affairs, 75 (1999), pp. 531-545.

${ }^{5}$ A recent study by Matthew Lindauer and Christian Barry, suggests that this belief is quite common. See Matthew Lindauer and Christian Barry, "Moral judgment and the duties of innocent beneficiaries of injustice", Review of Philosophy and Psychology, 2017, doi:10.1007/s13164-016-0329-9.

${ }^{6}$ Note that the wrong involved in keeping property from its rightful owner need not be explained by any version of the BPP. Returning stolen property to its rightful owner is a duty that plausibly relies on rationales that are
} 
In this article I critically engage with three recent and influential attempts at articulating a rationale for a version of the BPP. The aim of the paper is not to discount the BPP but to argue that each of these attempts fail critically at justifying the BPP for reasons which in many respects are similar. Furthermore, what motivates this article is not that I think we should reject any version of the BPP, but that I want to identify in some detail important problems that need to be overcome for a version of the BPP to have any good claim to be considered justified.

Proponents of the BPP have sought to justify the idea in a variety of ways. ${ }^{7}$ A wellestablished argument in this literature is found in a much-cited article by Daniel Butt, who appeals to the idea that taking the appropriate attitudes to a wrong, namely that of condemnation or regret, itself commits beneficiaries to the duty to give their benefits to the victims of those wrongs. According to Butt, failure to accept this commitment amounts to a form of inconsistency in our normative beliefs. In section 2 of this paper, I will argue that one reading of Butt's claim, which seems at least prima facie plausible, does not in fact single out beneficiaries of wrongs, but applies to everyone who can remedy the regrettable effects of wrongdoing. We can therefore accept a plausible version of Butt's claim, while we reject the BPP. Second, I argue that the reading Butt intends balances on a set of assumptions which we seem to have very good reasons to reject.

In the next two sections I turn to two recent attempts at justifying the BPP which are already receiving attention, but which have not been critically assessed in the literature thus

\footnotetext{
unconnected to the BPP and obtains even if no one benefits from the theft or from return of stolen property. I owe thanks to an anonymous referee for pointing this out to me.

${ }^{7}$ For a survey of the types of justifications that have been proposed in favor of the BPP, see Christian Barry and Robert Kirby, "Scepticism about beneficiary pays: A critique", Journal of Applied Philosophy, 34 (2017) pp. 285-300, at pp. 285-86.
} 
far. In section 3 I discuss Christian Barry and David Wiens' claim that innocent beneficiaries of wrongful harm typically sustain that wrongful harm by not giving their benefits to the victims of the wrong they benefited from. ${ }^{8}$ I argue that this argument is open to a similar objection to the one levelled against Butt's theory. Namely that a plausible reading of the argument applies to everyone capable of helping the victim and that we have to make seemingly absurd assumption in order to take on board the reading the authors intend. The reason I want to engage with this argument is first that it seems at the offset a strong attempt at justifying the BPP, which is already attracting attention. Furthermore, and although it is a co-written piece, it seems to represent the best and most detailed formulation of a rationale for the BPP that has come from one of the most prolific contributors to the recent literature on the idea.

In section 4 I start by noting that some authors have claimed that gains from wrongs come with a tainted title to ownership, and should therefore be given up, or "disgorged". A recent and seemingly promising defense of this view, proposed by Tom Parr, argues that the BPP may be grounded in the idea that immoral intentions should not be allowed to be completed. ${ }^{9}$ Like Barry and Wiens' article, Parr's seem to be motivated at least in part by the idea that a plausible version of the BPP needs to be restricted in certain ways to avoid having counterintuitive implications in certain cases. Parr's article deserves attention because in terms of identifying the most plausible rationale for the BPP, Parr seems to be on the right track by focusing on the intentions of the wrongdoer. ${ }^{10}$ However, I believe there are deep

\footnotetext{
${ }^{8}$ Barry and Wiens, "Benefiting from wrongdoing and sustaining wrongful harm", pp. 530-52.

${ }^{9}$ Parr, “The moral taintedness of benefiting from injustice", pp. 985-97.

${ }^{10}$ In "The normative implications of benefiting from injustice" Haydar and Øverland also argued that our judgment that beneficiaries owe something more to victims of injustice than mere bystanders, seem to be much stronger when the benefit is intentionally realized by the wrong, than in cases were the realization of the benefit
} 
problems with the account he proposes. The challenge I pose follows the structure from the two above: I argue that even if we accept the core idea Parr appeals to, namely the (arguably problematic) idea that it is (impersonally) bad for wrongful intentions to come to fruition, we nevertheless seem to have very good reasons to reject the idea that this commits us to Parr's version of the BPP.

Section 5 concludes by returning to the case which opened this article. I note that my discussion seems to have demonstrated that none of the rationales I have engaged with can vindicate the claim that the fact that Peter has benefited from an act that wronged you, implies that he has a particular responsibility (or a particular moral reason) to help you. I also note that this does not mean that the claim should be considered mistaken.

\section{The argument from attitudinal coherence}

An influential attempt at vindicating the BPP is found in a much-cited article by Daniel Butt, who argues that a beneficiary of a wrong has a reason or a duty to give up her benefits by virtue of her own condemnation of the wrong as wrong. In what follows I will argue that there is a reading of Butt's rationale which seems to be plausible, but which do not in any way motivate the BPP. On the other hand, there is a reading of the argument which would support the BPP, but which we should clearly reject. ${ }^{11}$

\footnotetext{
is accidental. While they showed that there is a clear difference in our intuitions between such cases, they did not provide any rationale for why we should accept that there is a moral difference. Parr's account is interesting partly because it provides such a rationale.

${ }^{11}$ Butt's arguments have been the subject of quite a lot of attention already. An excellent critical discussion is found in Kasper Lippert-Rasmussen, "Affirmative action, historical injustice, and the concept of beneficiaries", Journal of Political Philosophy, 25 (2017), pp. 72-90. There are arguably points of overlap between his account and mine. However, my main challenge against Butt is quite distinct. Furthermore, to the extent that my account
} 
In order to assess Butt's rationale for the BPP it is worth citing him at some length.

The most important passages in the article starts with the claim that

The individual's duty not to benefit from another's suffering when that suffering is a result of injustice stems from one's moral condemnation of the unjust act itself. In consequence, a duty to disgorge (in compensation) the benefits one gains as a result of injustice follows from one's duty not to so benefit. My claim is that taking our nature as moral agents seriously requires not only that we be willing not to commit acts of injustice ourselves, but that we hold a genuine aversion to injustice and its lasting effects. We make a conceptual error if we condemn a given action as unjust, but are not willing to reverse or mitigate its effects on the grounds that it has benefited us. The refusal undermines the condemnation. The belief that certain acts are wrong and should not be performed on account of their harmful consequences commits one to endorse the application of corrective justice to seek to undo the effects of injustice, insofar as doing so does not render oneself a victim, by making one worse off overall. $^{12}$

In elaboration on how we make a "conceptual error" by thinking that we can go about keeping our benefits from injustice, Butt writes:

If we actually wish that we were in a different kind of world, and think that such a world would be more just than our current world, surely it follows that we should seek

\footnotetext{
touches on some of the same themes as Lippert-Rasmussen's, I make important elaborations to what has already been argued. I am grateful to an anonymous referee for pointing this out to me.

${ }^{12}$ Butt, “On benefiting from injustice", p. 143.
} 
to make our world more similar to the counterfactual world in question? (...) If our moral condemnation of injustice, our regret that injustice has occurred, is to be taken seriously, it must be matched by action to remedy the effects of injustice (...). ${ }^{13}$

Inferring from this, it seems that the kind of error Butt is concerned with, consists of an incoherence within our attitudinal beliefs. We have attitudes, that is, about what past actions are wrong, and we have attitudes about what is required of us in terms of helping victims of those wrongs. According to Butt, beneficiaries that believe they are not required to give their benefits from wrongs to the victims of those wrongs, commit to an incoherence between these two attitudes. ${ }^{14}$

It seems to me that the normative force of Butt's claims about inconsistency roughly has two sources. First it is the claim that we cannot coherently reconcile our attitudes of condemnation and regret for a wrongful action, with the attitude that we can go about keeping our benefits, due to the fact that our benefit and the thing we condemn as wrong are causally linked the way they are. I will return to discuss this claim shortly. Before I do so however, I want to note the important fact that much of what Butt claims can also be interpreted in a second way. Plausible claims such that "our nature as moral agents" requires us to hold a genuine aversion to the lasting effects of injustice, or that any serious "regret that injustice has occurred", must be matched by willingness to act in order to remedy its (regrettable) effects, need not commit us to any version of the BPP at all. Butt may be right that if we are genuine and serious about our own regret or condemnation for the wrongful infliction of suffering on

\footnotetext{
${ }^{13}$ Butt, "On benefiting from injustice", p. 143.

${ }^{14}$ Butt does not use words such as "incoherent", however the idea that our attitude that we can go about keeping our benefits from wrongs is in conflict (or "undermines") our commitment to the belief that the act was in fact wrong, seem to indicate that the error Butt claims to have identified, involves some form of incoherence.
} 
others, then we must also see ourselves as required to help out the victim and remedy the suffering. However, and crucially, these are claims that do not in particular single out beneficiaries of injustice to help the victim. Rather they apply to everyone. The force of these claims does not depend on whether one has benefited from the wrong in question but rather depend on one's level of ability to help the victim. For someone very well off, helping the victim may not amount to much of a sacrifice. Failing to do so would then seem to reveal something about one's genuine aversion to what was done to the victim. Plausibly, the less of a sacrifice it would be to help, the less genuine would any regret at what was done to the victim seem to be for a person who chooses not to help the victim. Although you may agree that these claims are at least prima facie plausible, note that I am not defending them. All I am claiming is that they in fact carry a significant part of the normative weight in Butt's account, and they do absolutely nothing to motivate the BPP. We may wholeheartedly accept them and still reject the BPP.

Naturally, Butt has set out to defend the BPP (not the "Ability to Pay Principle"), so we need to focus on the part of his claims that actually can be used to single out beneficiaries of wrongs to help the victims of those wrongs. What seems to stand out in this regard is Butt's emphasis on the idea that condemning an act as wrong, entails a judgment that the act should never have been committed, or it implies a wish that the act had never happened, or an attitude of regret towards the fact that the act happened. If we agree that we desire (or something to that effect) that the act was never committed, something which seems eminently reasonable, then we have taken Butt's argumentative bait: Had the act never happened, Butt observes, then things would have been different. In the counterfactual world where the wrong never happened, the very counterfactual world that we seem to implicitly wish for by condemning the act as wrong, we would not have benefited. So, in effect, when we take the appropriate attitudes of condemnation, regret, wishing-that-it-had-never-happened, or so on, 
towards the wrongful act, then the same attitude towards having the benefit is implied as well. $^{15}$

The upshot here seems to be that if we are both beneficiaries of acts that we believe are wrong, and we are moral agents, in the meaning that we are prepared to take the appropriate attitude towards a wrongful act, then coherence requires that we have the attitude that we should give up our benefit in order to make our world more similar to the counterfactual world where the wrong never happened. If we fail to embrace this attitude, then the alternative is either to revise our self-perception as moral agents, or to revise our attitude that the act in question was in fact wrong. ${ }^{16}$

This amounts to a plausible argument. Recall therefore, our case involving you, me and Peter. Suppose that you explain Butt's reasoning to Peter and demand that he contributes to compensating you for what happened by giving you the equivalent of what he has benefited from my wrongful actions. How could Peter respond to this? Naturally, he could deny that he is a moral agent, or he could deny that he believes I wronged you and should not have done so. However, these options seem very unattractive.

\footnotetext{
${ }^{15}$ Butt's argumentative methodology seems to take the form of a transcendental argument. Standardly, transcendental arguments hold that given that we accept that one thing $\mathrm{Y}$ is the case, we must also accept that another thing X is the case: X follows logically from Y. See e.g. Stern, Robert, "Transcendental arguments", The Stanford Encyclopedia of Philosophy (Summer 2017 Edition), Edward N. Zalta (ed.).

${ }^{16}$ Arguably, there is some conceptual similarity with the kind of incoherence Butt claims is present in the attitudes of the beneficiary and the notion of being a hypocrite. Therefore, the claim may implicitly be that we are being hypocrites if we think an act is wrong, but are unwilling to "mitigate its effects on the grounds that it has benefited us". I mention this because perhaps it indicates what is at stake about making the error Butt thinks many beneficiaries of injustice make. However, nothing I am going to argue depends on the accuracy of this interpretation.
} 
Leaving such responses aside then, I believe that Peter could respond that Butt's argument takes the causal connection between the past and present to have an importance which we have no good reason to accept that it has. ${ }^{17}$ The point here is not that our attitudes about past actions are irrelevant for the coherence of our attitudes towards the presence. For instance, if I think that a case of torture that happened five years ago was immoral, it would seem quite incoherent if I also thought that should identical acts under identical circumstances happen right now, they would not be immoral. Rather, what there seems to be no reason to accept is that the causal connection between past and present means that we are required by coherence to have wishes, attitudes or desires for how the present world should be that describe a world that would have been realized if our wishes, attitudes or desires for the past had been realized. While it may seem obvious, it is also important to keep in mind the fact that our desires for the past cannot be realized. Peter may very well want to live in a world where I never hit you with my car, but that fact just does not provide him with any reason to give up his benefit. This is clearly the case because even if giving up the benefit makes the present seem more similar to the counterfactual world where I did not hit you with a car, giving it up does not change the fact that I hit you with my car. The act of giving up the benefit therefore cannot plausibly count as a rational response to the desire to live in a counterfactual world where I never hit you with my car. ${ }^{18}$

\footnotetext{
${ }^{17}$ The point here is not that this causal connection is not important per se. It certainly has great practical importance. For instance, the fact that things are as they are, is a result of what has happened in the past. This seemingly has the practical implication that if we wanted to set course for a different future than the one we are currently headed towards, this would be possible by changing something about the present.

${ }^{18}$ If we shift the focus to the reasons Peter would want to live in a counterfactual world, it is quite easy to see why he has a reason to compensate you. If Peter wanted to live in a counterfactual world because in that world you would have been spared all the suffering associated with being the victim of my actions, then trying to
} 
Furthermore, insisting that the causal connection between past and present in fact should be taken to have this importance for what the content of our attitudes about the present should be, comes at a very high price, because the logic of such a claim applies not simply to material benefits, or to benefits in particular at all. Rather it applies to anything in the universe that would have been different or would not have been at all, had not some wrongful act happened. In other words, it applies to all aspects of our lives. Take the fact that you are reading this article on how attempts to provide a theoretical justification for the BPP have failed. You reading this article would likely never have happened had it not been for the countless wrongful acts that have marred the history of humanity. After you have finished reading, you may want to forget the whole thing, but it would be very strange if you felt this way because of the fact that in the counterfactual world in which no wrongful act ever happened, I would not have written this article.

While this case may seem trivial, other cases are less so. Someone who condemns her father's act of raping her mother as wrongful should really not be taken to imply something about what her attitudes towards her own continued existence should be, just because in the counterfactual world in which her father never raped her mother, her mother has no child. Butt may of course respond that the right counterfactual world in such a case is the one where the procreational acts in question happened, but where everything was in fact consensual. Butt may claim that in light of this counterfactual world, the daughter has no reason to regret her own existence or desire that she did not exist. However, this really amounts to waving the white flag, because beneficiaries of slavery could likewise say that the relevant counterfactual world is the one where Africans gladly left their homelands and worked for no pay out of

mitigate that suffering by compensating you is a rational response to this reason. Importantly, however, this applies to everyone that can help alleviate the harm. It does not single out beneficiaries in any way. 
their own free will. In light of that counterfactual world, Butt's rationale provides no reason for these beneficiaries to give up their benefits.

Note that while I have argued here that there is no good justification for why the causal connection between past and present should be taken to have any importance for what the content of our attitudes about the present should be in order to be coherent with our attitudes about how the past should have been, I am making no general claim about the validity of reasons to correct past injustices, nor does my arguments imply such a general claim. ${ }^{19}$ Furthermore, I need not even deny that our own condemnation of an act as wrong can in fact present us with a reason to reverse or undo that wrong. Suppose, for instance, that Parker stole a ball from you that rightfully belonged to you, and then gave it to me. Suppose also that I recognize that Parker acted in a way that was wrong, and which he therefore should not have done. ${ }^{20}$ My reasons for making this judgment would presumably be that I believe that the ball is your rightful property. However, if I truly believe that the ball is your rightful property, then it seems that I must also believe that I should transact the ball back to you. Thus, my own reason for condemning the act as wrong and an act that should not have been done, presents me with a reason to give you the ball. It would seemingly be incoherent of me to believe that the ball rightfully belongs to you and also believe that I should keep the ball from you. Unfortunately, this reasoning seems to not work for the BPP. For instance, the fact that Peter has benefited from my act of hitting you with my car seems to not be the reason why we believe that my actions were wrongful and should not have been committed.

\section{The Argument from sustainment of wrongful harm}

\footnotetext{
${ }^{19}$ See footnote 18.

${ }^{20}$ This is a retelling of one of the cases Butt has appealed to in motivating his account. See Butt, "“"A doctrine quite new and altogether untenable": Defending the beneficiary pays principle", p. 340.
} 
Some theorists have argued that refusing to give up benefits from wrongful harm could possibly implicate beneficiaries in separate wrongs. ${ }^{21}$ The presence of someone accepting benefits may for instance encourage new wrongs in the future, by agents that are motivated to benefit these people by wronging others. Some cases of not giving up benefits may therefore contribute causally to new wrongful acts. Barry and Wiens make a somewhat similar, but more intricate claim, when they argue that by retaining the benefits of wrongful harm, beneficiaries tend typically to sustain that wrongful harm. On this view innocently benefiting is not wrong per se, but many cases of innocently benefiting fall into the category of sustaining wrongful harm:

An innocent beneficiary does not initiate the wrongdoing, nor is she complicit in the initial wrongdoing. However, an innocent beneficiary who sustains wrongful harm contributes to the persistence of the wrongful harm constituted by a violation of a claim held by the victim. ${ }^{22}$

Let's call this the "sustainment claim". The idea that it is wrong to sustain wrongful harm seems quite plausible, but it can be fleshed out in different ways. Someone who retains an object which is the rightful property of someone else, clearly sustains the violation against the owner's claims to ownership over that object. This is because someone that holds stolen goods can lift the violation of the owner's justified claims to ownership, by transacting it back to the owner. On this understanding, someone sustains the violation of a claim if they have a standing to (i.e. are in a position to) lift the violation of that claim once it has been incurred. Let us call this a "narrow sense" of sustainment of wrongful harm. This narrow sense appeals

\footnotetext{
${ }^{21}$ Barry and Kirby, "Scepticism about beneficiary pays: A critique”, p. 286.

${ }^{22}$ Barry and Wiens, "Benefiting from wrongdoing and sustaining wrongful harm", p. 547.
} 
to the sustainment of a violated claim against being treated in certain ways. It explains therefore what Barry and Wiens mean when they write that the wrongful harm in question is constituted by a violation of a claim held by the victim.

On the other hand (and from a certain kind of perspective) anyone who has the ability to mitigate wrongful harm, is sustaining that harm by choosing not to mitigate it. Let us call this the "broad sense" of sustaining wrongful harm. This broad sense does not need to appeal to any violated claim held by the victim. Instead it only points to the fact that the victim has been harmed by wrongdoing. On this broad account, sustaining wrongful harm has only to do with an unwillingness to help out on the part of those that have the ability to do so. The broad sense of sustaining wrongful harm therefore does not single out innocent beneficiaries to pay. My challenge against Barry and Wiens' position will be that they fail to show that innocent beneficiaries are typically guilty of sustaining harm in any other way than the broad sense. If I am correct, their idea of sustaining wrongful harm does nothing to show why beneficiaries have special responsibilities to remedy harms caused by the wrongs they have benefited from.

Barry and Wiens rationale rests on the claim that innocent beneficiaries often sustain harm in a very distinct way, which capable bystanders do not. They argue that this claim applies under the following two conditions:

(1) the beneficiary receives an item or quantum of value to which the victim of the wrongdoing has a claim and the victim's claim remains unresolved; or

(2) the beneficiary receives a benefit in violation of the victim's claim(s) on the wrongful practice or institution and the victim's claim(s) remain unresolved. ${ }^{23}$

\footnotetext{
${ }^{23}$ Barry and Wiens, "Benefiting from wrongdoing and sustaining wrongful harm", p. 543
} 
The first condition seems to apply to the most obvious types of cases of stolen or misplaced property. ${ }^{24}$ As such, this condition makes little headway for the BPP. None of the critics of the BPP need to deny that something which should be understood as the rightful property of someone, should be transferred back to that person if it has been wrongfully taken away from them or misplaced. It is the way the BPP moves further than a principle simply arguing for return of stolen or misplaced goods which is up for debate.

Consider then, the perhaps more interesting second condition. According to Barry and Wiens, this condition applies to the following type of case:

Missed interview Wanda and Brent are called to interview for the same job; they are the only candidates. Hank (...) steals Wanda's car. Consequently, Wanda misses her interview and Brent gets the job. ${ }^{25}$

Note that this case has more or less the exact same structure as the case I started this article by presenting. Let us therefore take a look at the reasoning behind the claim that Brent owes something to Wanda (or by extension that Peter owes something to you) by virtue of the sustainment claim:

\footnotetext{
${ }^{24}$ This condition could also apply to claims we have to items or quantums of value that we have in virtue of other normative ideas than justified property rights. However, I assume that it serves no purpose to simply say that we have a claim to items or quantums of value that have been realized by wrongs against us. This would seem to presuppose the validity of the BPP rather than to justify it.

${ }^{25}$ Barry and Wiens, "Benefiting from wrongdoing and sustaining wrongful harm", pp. 545-46. Another central example is called "no promotion" in which a company systematically favors men over women for promotion. The distinction between these cases is unimportant for my purposes. Whatever I say about the missed interview case applies also to "no promotion".
} 
Suppose each person has a general claim against their fellows from obstructing their participation in a fair employment process. [...] Hank obstructs Wanda's participation in a fair employment process. [...] Brent receives the job in violation of Wanda's claim to unobstructed participation in a fair employment process. Wanda's claim remains unresolved so long as Brent retains the job without working to rectify the situation. ${ }^{26}$

It seems clear from this explanation that the issue here is that Wanda's initial claim against obstruction in a fair employment process "remains unresolved", and is thereby sustained, as long as the beneficiary retains the benefit. If by "wrongful harm" we are referring to the violation of Wanda's claim against her fellows, then it makes sense to say that wrongful harm is sustained.

Suppose we accept that we have general claims against our fellows in the way described above. If Brent does not work to rectify the situation it seems plausible that he sustains the violation of Wanda's claim to participation in a fair employment process. This is plausible because Brent seems to be positioned in a way that makes it possible for him to undo the violation of Wanda's claim. After all, only Brent holds the job, and if he pleads with his boss to redo the hiring process by also considering Wanda, his boss may very well listen to him. Especially if he makes it clear that he will resign, should Wanda not also be considered for the position through a new interview. In terms of sustaining violations of claims, Brent is plausibly in a similar position to the possessor of stolen goods who has a standing to end the continued violation against the owner's claims against having her rightful property withheld from her.

\footnotetext{
${ }^{26}$ Barry and Wiens, "Benefiting from wrongdoing and sustaining wrongful harm”, p. 546. For the purposes of my discussion here, I will not question the idea that each person has such general claims against their fellows.
} 
It seems to me that this admission makes very little headway for the BPP, because beneficiaries will only very rarely have a standing to lift the violation of a claim. ${ }^{27}$ To illustrate this point, suppose that it is impossible to redo the hiring process even if Brent quits his new job. ${ }^{28}$ Under these assumptions Brent is in no position to lift the violation against Wanda's claim. If Brent quits his job in some kind of protest, Wanda will not be given a new chance at unobstructed participation. Brent keeping the job therefore does not sustain the violation of Wanda's claim to unobstructed participation. I expect that Barry and Wiens would still hold that Brent nevertheless has a special duty to make some other form of compensation to Wanda. For instance, in the form of a transfer of money to her. ${ }^{29}$ It seems that if Barry and Wiens want to argue that Brent owes Wanda some other form of compensation than an attempt to redo the hiring process (should such attempt fail or be otherwise impossible), then their argument would have to be that Brent also sustains the violation of Wanda's claim by not transferring say, a fitting sum of money to her. However, such an argument would clearly be mistaken because a claim to monetary compensation is not the same as a claim against being obstructed from participation in a fair employment process.

\footnotetext{
${ }^{27}$ Note that this claim does in fact make some small concessions to the relevance of the BPP. However, one should keep in mind that this concession depends upon accepting Barry and Wien's assumptions both that we have general claims against our fellows, and that we have the specific general claim they sketch in this case. I have accepted these claims only for the sake of argument, because I believe I can show that even so, their view largely collapses. I owe thanks to an anonymous referee for urging me to clarify this point.

${ }^{28}$ For instance, suppose that shortly after Brent is hired, the company discovers that it is in financial trouble and must cut costs. Therefore, they stop all new hiring. If Brent quits his job, the company will not seek to replace him.

${ }^{29}$ In the present example it may be possible to redo the hiring process. However, in most cases of interest for BPP proponents (that is, in most cases of wrongdoing), we simply cannot replay events in a fair way that undoes the injustice. Instead we may rely on some form of compensation for what has happened.
} 
Denying her money after she has been obstructed therefore cannot possibly sustain such an obstruction. It would be absurd to claim that giving her money would lift the obstruction to participation.

Barry and Wiens may respond that in cases were Brent has no option to influence the decision to also consider Wanda for the position, he still has a remedial duty to compensate because he holds the job. However, it is difficult to see why that could be. Brent is innocent of any wrongdoing, and in this case, he does not plausibly sustain the violation of Wanda's claim by keeping his job. Barry and Wiens may claim that even though Brent in this scenario does not sustain the violation of Wanda's claim against being obstructed to participation, he sustains the harm inflicted on her by the obstruction. It seems to me that such a claim would clearly be correct. However, such a response is of course also fatal to their view, because it fails to single out Brent for remedial duties. If Brent refuses to compensate Wanda for the harm of being obstructed, with a fitting amount of money, then he would sustain the harm inflicted on her only in what I have called the "broad sense" of sustaining harm. This follows from the fact that Brent is not the only one who can give Wanda money. Wanda may have a claim to monetary compensation for being harmed, but the sustainment claim provides no reason why this money should come from Brent. Brent is sustaining her claim to monetary compensation for harm in the exact same way as any other agent that is equally capable of compensating her.

Since the case involving Brent and Wanda corresponds well to our opening case, what I have said about Brent, is also true for Peter. Suppose therefore that it is not possible to simply redo the hiring process, either because too much time has passed, or because your injuries now make you unqualified for the job. Moreover, suppose that you ask Peter to compensate you by giving you what he has benefited on the grounds that he sustains the violation of a claim you have against unobstructed participation in a fair employment process 
(or something similar). Peter could answer that he is not in fact sustaining the violation of such a claim by not compensating you, because his offer of compensation to you does not lift the violation of this claim. Compensation could relieve the harm that has befallen you, but this fact does not show why Peter in particular has a special responsibility to compensate you that other innocent agents do not share.

Towards the latter part of their article, Barry and Wiens argue that their rationale applies to cases such as

Sweatshop. Textile workers in an underdeveloped country work for unacceptably low wages and often in unhealthy or dangerous working conditions. Consequently, multinational textile firms can sell their products at lower prices than if they had paid their employees minimally decent wages and provided adequate working conditions. $[\ldots]^{30}$

According to Barry and Wiens, consumers that buy the clothes have a special responsibility towards the workers

[...] because they receive the benefit of cheap clothing in violation of the workers' claims on the design of institutions governing the labor market and its regulation." 31

\footnotetext{
${ }^{30}$ Thomas Pogge, "Severe poverty as a violation of negative duties", Ethics \& International Affairs 19 (2005), pp. 55-83, at p. 72; Barry and Wiens, "Benefiting from wrongdoing and sustaining wrongful harm", p. 548

${ }^{31}$ Barry and Wiens, "Benefiting from wrongdoing and sustaining wrongful harm", p. 549. Note that Barry and Wiens assume for the sake of argument that the consumers are in fact innocent. Naturally, that is not necessarily the case. For instance, by virtue of their membership in powerful states, such consumers may be collectively guilty of cooperating in the imposition of an unjust institutional order that harms the workers. See e.g. Pogge, "Severe poverty as a violation of negative duties", p. 71. As Pogge argues, members of affluent states may owe
} 
If we take the broad view of sustaining wrongful harm, it should be clear that anyone who elects to not compensate the workers, sustains whatever harm is brought on by the wrongful practice. As such consumers seem to owe the workers the same as other capable agents do. Barry and Wiens may respond that the consumers are sustaining the violation of the worker's claims by keeping their benefits, but it is difficult to see how that could be. The violated claim seems to be a claim to have fair institutions governing the labor market and its regulation. No one seems to be put in a position to lift the violations of the worker's claims against an unjust institutional design merely by receiving the benefits of such violations. ${ }^{32}$

\section{The "immoral plan" argument}

Some theorists have sought to justify the BPP by an appeal to the idea of moral taint. According to Robert Goodin, if material wealth at some point was acquired by way of past wrongs, this fact "taints" the title to such goods today ${ }^{33}$ Suppose for instance that someone owes their material wealth, at least in part due to some horrible wrong that happened 200 years ago. According to Goodin, this makes that wealth tainted. The innocent beneficiary in question should therefore give up or "disgorge" her gains. ${ }^{34}$

\footnotetext{
repair because they are responsible for imposing an unjust institutional order on the world's poor. To the extent that buying the cheap clothes is part of what contributes to the imposition, consumers are clearly not innocent. Moreover, it is not access to cheap clothes that makes the consumers in question members of powerful nations that could change the global institutional order.

${ }^{32}$ However, see footnote 31 .

${ }^{33}$ Goodin, "Disgorging the fruits of historical wrongdoing", p. 487.

${ }^{34}$ Goodin "Disgorging the fruits of historical wrongdoing", p. 482. It is worth mentioning that since this account focuses on duties to disgorge benefits, it isn't clear that it explains why or if beneficiaries have reasons to give their benefits to the victims of the wrongs they have benefited from, rather than for some other worthy cause.
} 
Although the word "taint" is suggestive, the link between the presence of taint and the requirement to disgorge needs to be explained. It is possible that the tainted benefit, taints the morality of the holder of that benefit, so to speak. However, this is clearly not an appealing argument. First, it seems quite mysterious, suggesting some contagious property of moral taint. Second, it seems that such benefits should not be redistributed at all, but rather destroyed. Redistribution, after all, would lead to a further spreading of the taint. I think that this reading of Goodin is almost certainly a misunderstood one. Perhaps he does not mean that "moral taint" accompanies goods causally connected to wrongs, but that material entitlements that can be causally attributed to (historical) wrongs are much weaker than entitlement that are not (all else being equal). However, if moral taint is not doing the normative work here, then it is unclear what rationale is actually doing the normative work. If all Goodin means by saying that past wrongs taints entitlements to present goods, is that entitlements to present goods are weaker if they are causally connected to past wrongs, then that begs the question of why that makes such entitlements weaker.

In a recent article, Tom Parr defends a version of Goodin's claim that beneficiaries of wrongs should disgorge their benefits. ${ }^{35}$ He argues that ownership over a good becomes morally tainted "[...] when the recipient's possession of it is the intended result of injustice ${ }^{36}$ Furthermore, he argues that the underlying rationale here is that the completion

\footnotetext{
${ }^{35}$ Parr's argument has also recently been endorsed in an article by Göran Duus-Otterström, "Benefiting from injustice and the common-source problem”, Ethical Theory and Moral Practice, 20 (2017), pp. 1067-1081.

${ }^{36}$ Parr, "The moral taintedness of benefiting from injustice", p. 994. Plausibly, the meaning of "taint" here is as suggested above, simply that entitlement over a benefit is weaker than entitlement over things would otherwise be, all else being equal. I mention this because that seems to me the most charitable interpretation. However, nothing I say rides on this interpretation.
} 
of an immoral plan is impersonally bad. ${ }^{37}$ According to Parr, this generates “(...) an extra reason for the recipient to relinquish the good or the benefit it yields". ${ }^{38}$ In order to back up this argument further, he asks us to consider the following pair of cases:

Genetic Luck: A is born with two eyes and B is born with none. We can cheaply and painlessly gift one of A's eyes to B, thereby ensuring equality of sight.

Eye theft: $\mathrm{C}$ has two eyes and $\mathrm{D}$ is born with none. $\mathrm{C}$ was born with one eye, and her parents stole a second eye from an unknown victim. We can cheaply and painlessly gift one of C's eyes to D, thereby ensuring equality of sight.

According to Parr, we have more compelling moral reasons to perform the eye transfer in the Eye Theft case than in the Genetic Luck case. ${ }^{39}$ He claims that this should be evident from our intuitions about the two cases. ${ }^{40}$

It seems that in order to evaluate Parr's two cases against each other, we should assume that both $\mathrm{A}$ and $\mathrm{C}$ are equally attached to their sets of eyes. Furthermore, we should assume that their life plans are equally connected to reasonable expectations about continuing to have two eyes. These assumptions should isolate the moral taint argument, from other

\footnotetext{
${ }^{37}$ This argument seems to amount to what Derek Parfit calls "reverse consequentialism" since it holds that the impersonal badness of an act is decided (at least in part) by the intrinsic wrongness of the intention behind the act, rather than the amount of good or bad consequences the act yields. See On what matters: Volume three, (Oxford: Oxford University Press, 2017), p. 350.

${ }^{38}$ Parr, "The moral taintedness of benefiting from injustice", p. 994.

${ }^{39}$ Presumably provided that it is not the eye that $\mathrm{C}$ was born with that is up for redistribution. I am grateful to an anonymous referee for pointing this out to me.

${ }^{40}$ Parr, "The moral taintedness of benefiting from injustice", p. 994.
} 
notions about how entitlement to things may be morally grounded. In order to imagine this, we could for instance assume that the wrongful transfer of C's second eye happened in C's infancy, and that $\mathrm{C}$ and $\mathrm{A}$ are now both adults. Having both grown up with two eyes, both $\mathrm{A}$ and $\mathrm{C}$ have equally strong and reasonable feelings of entitlement to their respective body parts.

When making these considerations, it seems to me that the little intuitiveness there is to Parr's example, more or less disappears. Provided both A and C are equally attached to their eyes in the various relevant ways, and there is no option of giving the eye back to its original holder, our intuitions about the cases, I would suggest, do not differ much. Perhaps this objection would not move Parr much, because when it comes to intuitions people tend to not always agree, but I take it that whatever pull of intuition that remains is at best weak. It seems to me that isolated intuitions about cases, and weak ones in particular, are not particularly robust pieces of evidence in favor of general moral principles. In order to get at Parr's defense of the BPP, we would therefore do best to focus on his more principled rationale.

When claiming that it would be impersonally bad for immoral plans to be completed, Parr refers to an article by Jeff McMahan, were the latter discusses the idea that we may have stronger moral requirements to save people from dying from an attempt at murder, than to save someone from, say, an accident. ${ }^{41}$ The reasoning behind this is that the former does not only stop harm, but also stops wrongful intentions from coming to fruition. Suppose for instance we could either stop a murderer's bullet from reaching and killing a targeted victim,

\footnotetext{
${ }^{41}$ Jeff McMahan "Humanitarian intervention, consent, and proportionality", Ethics and humanity: Themes from the philosophy of Jonathan Glover, eds. N. A. Davis, R. Keshen, J. McMahan, (Oxford: Oxford University Press, 2010) pp 44-71, at pp. 60-62. McMahan discusses the relevance of this idea for the case of military intervention.
} 
or we could stop a small asteroid from landing on someone and thereby killing them.

According to the view McMahan discusses, it may be better to prevent the wrongful intentions from being completed than to prevent the natural event.

It is worth noting, that one well-known problem for this kind of view, is that the moral badness of trying to kill someone seems to have come about by the would-be murderer acting on her intentions to try to kill the victim. It seems not possible to reverse this badness, because saving the person from the bullet does not erase the fact that someone in fact acted on her intentions to try to murder someone. ${ }^{42}$ It is therefore unclear how it could be better to stop the bullet than to stop the asteroid (all else being equal). However, suppose that we accept that things would in fact be impersonally better if we stopped or undid the completion of an immoral intention rather than reversed the same effects of an accident, because of the impersonal badness of wrongful intentions coming to fruition. It seems to me that accepting this does not vindicate Parr's argument, because in the eye theft case, the victim has already been harmed or wronged by the wrongdoer. Our transplant of one eye from C to D would therefore not change (or in some way undo) the fact that the unknown victim (whom we may call E) has been subjected to an act which consists of the completion of an immoral intention. No amount of transactions between $\mathrm{C}$ and $\mathrm{D}$ could prevent $\mathrm{E}$ from having her eye taken away from her.

I think that this objection to the connection between Parr's version of the BPP and the idea that it is impersonally bad for immoral intentions to be completed is worth making. However, in making it, I have not fully accounted for what seems to be Parr's view. Parr would likely respond that we must view not just the completion of the immoral intention to steal from E as something bad. Instead we should think of the completion of the whole plan of both stealing the eye away from the unknown victim and the gifting of that eye to one-eyed $\mathrm{C}$,

\footnotetext{
${ }^{42}$ See e.g. Derek Parfit, On what matters: Volume three, pp. 355-357
} 
as one entity that is singularly bad. The reason we should think this way is that these intentions are connected by being part of the same "grand plan" in the wrongdoer's thinking. Let's call this "the grand plan claim". It seems that accepting this claim would commit us to also accept that something (impersonally) bad would be undone if the stolen eye were taken away from $\mathrm{C}$, even if it could not be given back to the victim. However, apart from the fact that it would make Parr's theory more coherent, I cannot think of a reason why we should accept it.

While I think it is very unclear why we have reason to accept the grand plan claim, I think there are at least two very strong reasons to reject it. Consider first the fact that even an overall immoral plan could involve at least some intentions which are not at all immoral. A bank robber may have planned to rob the bank as part of a larger plan to benefit a sick child. It may be true that it is wrong to rob the bank even if doing so benefited the sick child, but this does not show that there is something objectionable about the intention of benefiting the sick child. Likewise, the intention of gifting a child a second eye is not an immoral intention. It is clearly a good intention. ${ }^{43}$ Naturally, we could undo the completion of the good intention to benefit $\mathrm{C}$ or the sick child, simply by taking the benefits away from them or by harming them in some other way equivalent to what they have benefited. My point here is not to argue that it is implausible that we have reason to do so. ${ }^{44}$ My point is that it seems self-defeating, or even somewhat absurd, that a view which is based around an objection against immoral intentions coming to fruition, could give us reason to undo the completion of what is clearly a

\footnotetext{
${ }^{43}$ This seems correct to me even if the intentions for the means of gifting the eye, are in fact immoral.

${ }^{44}$ Naturally, there may be good reasons to reverse the sick child's reception of benefits. If the child becomes in possession of stolen goods, then we may justify giving these benefits back to their legal owners by appealing to some idea of property rights. It is important to note, however, that we would not then be appealing to the impersonal badness of a grand plan being completed.
} 
good intention. ${ }^{45}$ The "grand plan" claim responds to this charge, by telling us we have reason to undo the completion of the good intention to benefit $\mathrm{C}$, because of the mental connection which existed in the mind of the wrongdoer between this good intention and the immoral intention to steal an eye. But only the fact that there exists such a mental connection in the head of the wrongdoer, seems like a contrived justification for undoing a good intention.

One response to this line of argument may be that for the kind of analysis I am making here, it is not in fact plausible to isolate parts of an overall immoral plan. I could possibly answer that it seems perfectly plausible to me, and leave it to the reader to judge whether this invalidates my argument or not. However, I could also respond by rephrasing my point. I could say that there are good and bad things about the intentions that form an immoral plan, and the fact that someone is intended to benefit does not seem to count among the bad things. Or else, I could say that the immoral part of an immoral plan or intention to harm someone in order to benefit someone else seems not to be the part of the plan which involves benefiting someone. ${ }^{46}$ These answers seems very plausible to me.

My second worry with the "grand plan" claim is that its theoretical implausibility is complemented by the fact that it also gives rise to clearly implausible judgments about cases. Consider the difference between

\footnotetext{
${ }^{45}$ Note that if we only wanted to undo the completion of the immoral intention to steal an eye, we could not in this case succeed, because the rightful owner of the eye can no longer be found. This fact alone does not, of course, explain why we should undo the good intention of benefiting $\mathrm{C}$ as some sort of second best measure. ${ }^{46}$ I am grateful to an anonymous referee for pressing me on this point.
} 
Eye theft ${ }^{*}$ : $\mathrm{C}$ has two eyes and $\mathrm{D}$ is born with none. $\mathrm{C}$ was born with one eye, and her parents therefore stole a second eye from E. By now E is dead. We can cheaply and painlessly gift one of C's eyes to D, thereby ensuring equality of sight. ${ }^{47}$

Eye theft 2: C has two eyes and D is born with none. C's mother once stole an eye from $\mathrm{E}$ for no particular reason. By now $\mathrm{E}$ is dead. When $\mathrm{C}$ was born with one eye, her mother gave her the stolen eye. We can cheaply and painlessly gift one of C's eyes to $\mathrm{D}$, thereby ensuring equality of sight.

In Eye theft 2 the immoral intention to steal an eye, and the good intention to gift someone an eye does not form parts of the same grand plan. According to Parr, it would seem, we would therefore have stronger reason to ensure equality of sight in Eye theft 1 than in Eye theft 2 . This conclusion is clearly implausible. When it comes to the judgment of whether we should ensure equality of sight or not, there shouldn't be any difference between these cases.

In conclusion, it seems that there are many problems with the "immoral plan" argument. My main charge however, has been that even if we accept that it is (impersonally) bad when immoral intentions or plans are allowed to be completed, we can comfortably reject Parr's version of the BPP, because the part of the overall immoral intention or plan to harm someone in order to benefit someone else, which is the part about benefiting someone, seems not to be the immoral part of the overall intention. To once again return to the case we started with: Suppose you tell Peter to give you his benefits on the grounds that doing so would undo the completion of my immoral plan or intentions. Peter may answer that he agrees that immoral things, including intentions and plans, should not be allowed to remain completed.

\footnotetext{
${ }^{47}$ Here "Eye theft*" is equivalent to "Eye theft", but the wording has been altered in order to highlight the structural difference between "Eye theft*" and "Eye theft 2".
} 
He may also agree that it was immoral of me to intend to run you over. However, he can very plausibly deny that my intention to benefit him features among the immoral things about my overall immoral intentions or plans. Parr's rationale does not seem to have the resources to rebut this kind of perfectly reasonable response. The immoral part of my intentions, Peter may hold, was the part that involved intending to harm you. Furthermore, while we may have reason to undo the completion of that intention by repairing the harm done, such a rationale does not single out innocent beneficiaries from other innocent agents.

\section{Conclusion}

I started out this article with the story of a person who realizes the benefit of a rare and lucrative job opportunity for his friend Peter, by deliberately running over another person with his car. I noted that it seems plausible that in such a case, Peter has particularly strong moral reasons to help the victim. My discussion of three recent attempts to explain what the rationale for such a claim could be, has, in my opinion, demonstrated that these three attempts cannot plausibly vindicate the claim. Even if we should accept that the completion of an immoral intention is impersonally bad, or even if we have certain general claims against our fellows, whose violation sometimes is sustained by the inaction of those that are in a position to lift these violations, or even if our genuine regret or condemnation for the wrongful infliction of suffering on others may require us to help out the victim in order to remedy the suffering, we seem to have no reason to accept the BPP. The theories I have discussed in this article appeal to these normative ideas, but they can only find support for the BPP by making additional assumptions which appear to be clearly implausible.

Arguably, my discussion adds fuel to the fire for a recent criticism of the BPP, which denies any independent moral relevance to the BPP and argues that any plausible version of the principle simply collapses into other principles considered to be supported by more robust 
rationales, such as the idea that inequalities that are due to bad luck are morally objectionable. ${ }^{48}$ My aim however, has not been to argue for a rejection of the BPP as such. Furthermore, my aim has not been to explain away the force of examples such as the one I opened with. My aim has only been to show how three recent and seemingly plausible attempts to justify the BPP have failed and are in critical need of elaboration and revision if they are to be salvaged. ${ }^{49}$

\footnotetext{
${ }^{48}$ See Robert Huseby, “The beneficiary pays principle and luck egalitarianism”, Journal of Social Philosophy, 47 (2016), pp. 332-49; Carl Knight, “Benefiting from injustice and brute luck”, Social Theory and Practice, 39 (2013), pp. 581-98 and Lippert-Rasmussen, “Affirmative action, historical injustice, and the concept of beneficiaries".

${ }^{49}$ I am grateful to an anonymous referee for pressing me on this point.
} 